\title{
Protect and Counter-attack: Nutritional Supplementation with Essential Amino acid Ratios Reduces Doxorubicin-induced Cardiotoxicity in vivo and promote Cancer Cell Death in vitro
}

\author{
Giovanni Corsetti ${ }^{1^{*}}$, Vincenzo Flati $^{2}$, Patrizia Sanità ${ }^{2}$, Evasio Pasini ${ }^{3}$ and Francesco Saverio Dioguardi ${ }^{4}$ \\ ${ }^{1}$ Department of Clinical \& Experimental Sciences, Division of Human Anatomy \& Physiopathology, University of Brescia, Brescia, Italy \\ ${ }^{2}$ Department of Biotechnological and Applied Clinical Sciences, University of L'Aquila, L'Aquila, Italy \\ 3"S. Maugeri Fundation", IRCCS, Cardiology Rehabilitative Division, Medical Centre of Lumezzane, Lumezzane (Brescia), Italy \\ ${ }^{4}$ Department of Internal Medicine and Community Health, University of Milan, Milan, Italy
}

"Corresponding author: Giovanni Corsetti, Department of Clinical \& Experimental Sciences, Division of Human Anatomy and Physiopathology, University of Brescia, v.le Europa, 11; 25124 Brescia, Italy, Tel: +39 030 3717484; Fax: +39 030 3717486; E-mail: giovanni.corsetti@unibs.it

Received date: Jul 13, 2015; Accepted date: Aug 14, 2015; Published date: Aug 16, 2015

Copyright: ( 2015 Corsetti G, et al. This is an open-access article distributed under the terms of the Creative Commons Attribution License, which permits unrestricted use, distribution, and reproduction in any medium, provided the original author and source are credited.

Keywords: Doxorubicin; Cardiotoxicity; Heart; Cancer; Essential aminoacids

\section{Commentary}

Human and experimental data show that nutritional supplementation with a specific mixture of essential amino (EAA) improves both mitochondrial function and biogenesis and reduces either ROS formation or apoptotic drive in myocytes [1-2]. Supplementation with EAA is also effective in humans when tested in patients with cardiac dysfunction [3]. Doxorubicin (Doxo), an effective cancer chemotherapy agent, causes severe cardio-toxicity due to mitochondria damage, production of reactive oxygen species (ROS) and cell apoptosis with myofibrillar disarrangement, which in turn induces chronic heart failure. Pathogenesis of toxicity, as reported by Zhang et al. [4] is connected to the binding of Doxo to topoisomeraseIIb , which triggers a complex cascade of events, altering the DNA response and apoptosis pathways and triggering a marked alteration in the transcriptome, that selectively affects oxidative phosphorylation and mitochondrial biogenesis in cardiomyocytes. As a result, Doxoinduced cardiotoxicity limits optimal drug-dose use, reducing its potential therapeutic effects in cancer patients [5].

Consequently, we hypothesized that supplementation with EAA would blunt Doxo cardio-toxicity, but we also tested if this would happen without interfering with the Doxo therapeutic effects on cancer cells. We used C57BL/6 mice fed on a normal diet and i.p. injected with a single saline or Doxo- $\mathrm{HCl}(15 \mathrm{mg} / \mathrm{kg}$, from SigmaAldrich) injection to induce cardiomyopathy [6], with or without oral supplementation of EAA $(1.5 \mathrm{~g} / \mathrm{kg})$. After 14 days, the heart was collected and morphologically evaluated by optical and electron microscopy. In addition, to test whether EAA supplementation negatively interferes with the Doxo anticancer action, we treated different cancer cell lines $\left(3 \times 10^{5}\right.$ cells/well in DMEM medium of HCT116 colon carcinoma; MCF7 mammary gland carcinoma; M14 melanoma), with Doxo $(0.7 \mathrm{microg} / \mathrm{ml})$ and with or without EAA (1\% w/v). Untreated cancer cell lines (cultured in DMEM only) were used as controls. The osmolarity of the culture medium was the same for all groups. After 24 hours the cells were counted with the Trypan blue dye exclusion assay to distinguish live from dead cells.

The in vivo experiments showed that Doxo significantly lowered body weight $(22.59 \pm 1.33 \mathrm{~g}$ vs $30.12 \pm 1.4 \mathrm{~g}$. $\mathrm{p}<0.05)$ and heart weight $(0.12 \pm 0.01 \mathrm{~g}$ vs $0.17 \pm 0.01$ g. $\mathrm{p}<0.05)$ compared to the control group.
Furthermore, Doxo induced morphological alteration of cardiomyocytes with giant and irregularly shaped nuclei with condensed chromatin (Figure 1a A-C). In addition, Doxo impaired cellular distribution, morphology and the number of mitochondria (24 \pm 2.8 vs $31.62 \pm 5.5 \mathrm{Nmit} / 100 \mu 2 . \mathrm{p}<0.05)$. Interestingly, EAA supplementation of Doxo-treated animals protected normal heart weight $(0.16 \pm 0.01 \mathrm{~g}$ vs $0.12 \pm 0.01 \mathrm{~g} . \mathrm{p}<0.05)$ and preserved cardiomyocytes architecture, mitochondrial morphology and number $(28 \pm 2.8$ vs $24 \pm 2.8 \mathrm{Nmit} / 100 \mu 2$. p <0.05) (Figure 1a D-F).

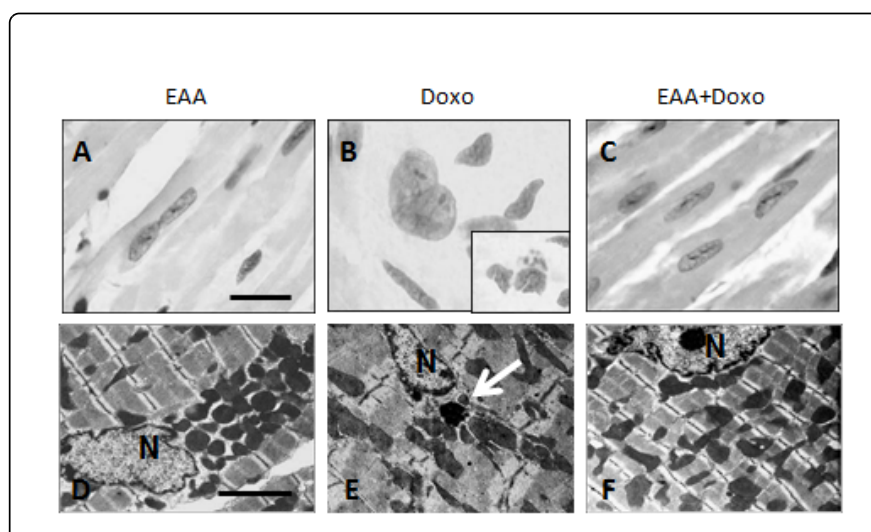

Figure 1a: (A-C) Eosin/Hematoxilin staining (Scale bar 10 $\mu$ ), and (D-F) electron microscopy pictures (Scale bar $1.5 \mu$ ) according to the groups EAA, Doxo, EAA+Doxo. The white arrow indicate a dense body (cellular debris). $\mathrm{N}$ = nucleus.

The in vivo findings were partially surprising because previous studies had shown that EAA nutritional supplementation stimulates mitochondrial biogenesis and endogenous defences against ROS. The consequences were: reduced cell damage, improved cellular energy production and preserved muscular structure, which finally increased life span of aged animals [1].

As expected, the in vitro experiments confirmed the Doxo action on cancer cells, causing about $60 \%$ of cell death vs untreated (control) cell after $24 \mathrm{~h}$. On the contrary and surprisingly, EAA administration with or without Doxo, increased cancer cell mortality (Figure 1b). Interestingly, EAA alone increased the apoptotic markers: cleaved- 
Citation: Corsetti G, Flati V, Sanità P, Pasini E, Dioguardi FS (2015) Protect and Counter-attack: Nutritional Supplementation with Essential Amino acid Ratios Reduces Doxorubicin-induced Cardiotoxicity in vivo and promote Cancer Cell Death in vitro . J Cytol Histol 6: 354. doi:10.4172/2157-7099.1000354

Page 2 of 2

Caspase 3 (0.75 fold) and Bax (2.7 fold) in isolated cancer cells (Figure 1c).

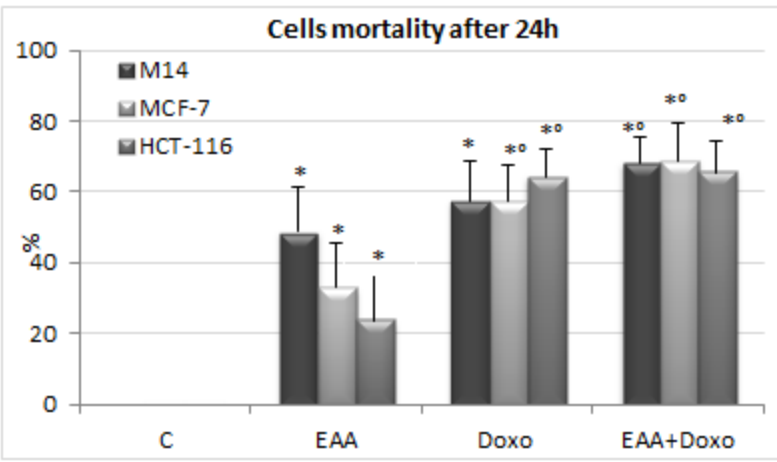

Figure 1b: Mortality after $24 \mathrm{~h}$ of cancer cells lines untreated (C) and treated with EAA, Doxo and EAA+Doxo. Results are expressed as $\%$ increase compared to time zero ( $\mathrm{n}^{\circ}$ of plated cells $\left.=3 \times 10^{5}\right)$. SNK-test ${ }^{*} \mathrm{p}<0.05$ vs $\mathrm{C}$ and ${ }^{\circ} \mathrm{p}<0.05$ vs EAA.

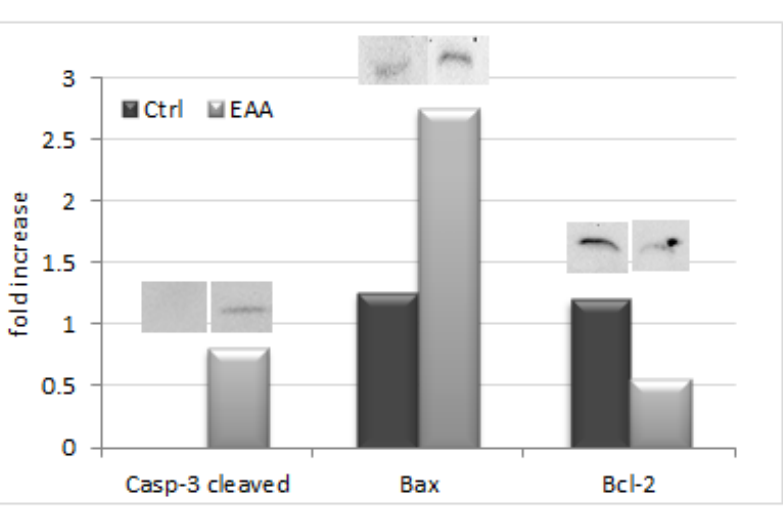

Figure 1c: Relative fold increase of apoptotic markers in HCT116 cell line untreated and treated with EAA.

We hypothesize that cancer cells are most dependent on the environmental availability of non-EAA for cell signalling, protein synthesis and cell proliferation. Therefore, we suggest that a "positive imbalance" between EAA and non-EAA may alter cancer cells environment and possibly trigger a signalling cascade which in turn induces a series of events incompatible with proliferation and survival of cancer cells. Further studies are in progress to clarify the mechanisms possibly connected to these intriguing findings.

\section{Disclosure}

The authors declare no conflict of interest except F.S. Dioguardi who is inventor and owner of US patents: $\mathrm{N}^{\circ}$-US6218420 B1. Compositions based on amino-acids for preventing and treating alimentary overloads in conditions of elevate body nitrogen requirements, without causing calcium losses. $\mathrm{N}^{\circ}$-US7973077 B2: Amino acid based compositions for the treatment of pathological conditions distinguished by insufficient mitochondrial function, and other patents pending on different amino acids based formulations.

\section{Acknowledgement}

This work was funded by the Fondo di Ateneo ex $60 \%$ to G.C and V.F.

\section{References}

1. D'Antona G, Ragni M, Cardile A, Tedesco L, Dossena M, et al. (2010) Branched-chain amino acid supplementation promotes survival and supports cardiac and skeletal muscle mitochondrial biogenesis in middleaged mice. Cell Metab 12: 362-372.

2. Corsetti G, Pasini E, D'Antona G, Nisoli E, Flati V, et al. (2008) Morphometric changes induced by amino acid supplementation in skeletal and cardiac muscles of old mice. Am J Cardiol 101: 26E-34E.

3. Scognamiglio R, Negut C, Palisi M, Dioguardi FS, Coccato M, et al. (2008) Effects of oral amino acid supplements on cardiac function and remodeling in patients with type 2 diabetes with mild-to-moderate left ventricular dysfunction. Am J Cardiol 101: 111E-115E.

4. Zhang S, Liu X, Bawa-Khalfe T, Lu LS, Lyu YL, et al. (2012) Identification of the molecular basis of doxorubicin-induced cardiotoxicity. Nat Med 18: 1639-1642.

5. Zhou S, Starkov A, Froberg MK, Leino RL, Wallace KB (2001) Cumulative and irreversible cardiac mitochondrial dysfunction induced by doxorubicin. Cancer Res 61: 771-777.

6. Suliman HB, Carraway MS, Ali AS, Reynolds CM, Welty-Wolf KE, et al. (2007) The $\mathrm{CO} / \mathrm{HO}$ system reverses inhibition of mitochondrial biogenesis and prevents murine doxorubicin cardiomyopathy. J Clin Invest 117: 3730-3741. 